\title{
TANNIN AND ANTIOXIDANT STATUS OF FERMENTED AND DRIED Sorghum bicolor
}

\author{
Tolulope Dorcas Olawole ${ }^{1}$, Anuoluwa Tenifayo Olalere ${ }^{1}$, Oladipupo Alaba \\ Adeyemi $^{1}$, Ogi Okwumabua ${ }^{2}$ and Israel Sunmola Afolabi ${ }^{1, *}$ \\ ${ }^{1}$ Department of Biochemistry, College of Science and Technology, Covenant University, \\ Ota, 100122, (Ogun) Nigeria \\ ${ }^{2}$ Department of Pathology \& Population Medicine, Midwestern University, \\ Glendale, 85305, (Arizona) USA \\ *E-mail : afolabisunmola@yahoo.com
}

ABSTRACT

The effects of some processing and extraction techniques on the tannin content and antioxidant activities of Sorghum bicolor (Linn) were evaluated. The ethanolic, methanolic and water extracts from the sorghum seeds were assessed after being fermented, or oven-dried for 0 (OVD-0), 30 (OVD-30) and 60 (OVD-60) mins, along with those of the chaff collected after fermentation, and the unprocessed sorghum (control). Tannin, total flavonoids, total phenol, polyphenol contents and 2, 2-diphenyl-1-picrylhydrazyl (DPPH) radical scavenging analysis were determined. All the processing techniques combined with the extraction methods significantly reduced $(\mathrm{p}<0.05)$ the tannins. OVD-30 combined with methanol extraction, and all the oven-drying techniques combined with aqueous extraction significantly increased $(\mathrm{p}<0.05)$ the flavonoids contents. Flavonoids levels in other methanol extracts and the ethanol extracts of sorghum seeds subjected to oven-drying methods were reduced significantly $(\mathrm{p}<0.05)$. The amount of phenolic extracted with both ethanol and methanol significantly increased $(p>0.05)$ during the period of oven-drying. The phenolic contents in the seeds were reduced significantly $(\mathrm{p}<0.05)$ when extracted with an aqueous solution. The amount of polyphenols was increased significantly $(\mathrm{p}<0.05)$ by ethanol extraction when treated with air-drying $(\mathrm{OVD}-0)$. The DPPH scavenging activity was increased significantly $(\mathrm{p}<0.05)$ by the processing methods when subjected to either aqueous or methanolic extraction. Fermentation and oven-drying are a highly effective method of reducing the anti-nutritional factors of sorghum. Therefore, the therapeutic values of the processed sorghum seeds may be improved during consumption.

Keywords: Food, Processing, Fermentation, Drying, Anti-nutrients, Antioxidant

○ RASĀYAN. All rights reserved

\section{INTRODUCTION}

Sorghum (Sorghum bicolor (Linn.) Moench) belongs to the Poaceae family and is the fifth ( $5^{\text {th }}$ ) amongst the most vital cereal such as wheat, rice and barley. It is one of the most well-known and widely cultivated crops worldwide. Currently, different types of species of the grain have been described. These include sweet sorghum, grass sorghum, grain sorghum, forage sorghum, biomass sorghum, sorghumSudan grass hybrids (Sorghum bicolor x Sorghum bicolor var. sudanense), Sudan grass (Sorghum bicolor ssp. drummondii) and broomcorn ${ }^{1,2}$. Sorghum is mostly found in the sub-tropical and tropical region of all continents apart from Antarctica. Sorghum can easily adapt to warm, hot and even dry agro-ecologies. It is the cheapest source of energy, providing above $80 \%$ of energy for human and animals especially in the developing countries. Countries like USA, China, India, Nigeria, Mexico, Argentina, Sudan and Egypt are the top of the global production chart of sorghum ${ }^{3,4}$. Sorghum is usually consumed either after it has been processed into flour or as a grain during preparation of traditional meals such as bisi (popped sorghum), ugali (fermented porridge), uji (unfermented porridge), buns (fermented or unfermented dough), chapatti (flat bread), pombe (alcoholic beverage) and a non-alcoholic beverage, known as togwa ${ }^{5}$.

Rasayan J. Chem., 12(2), 523-530(2019)

http://dx.doi.org/10.31788/RJC.2019.1224066

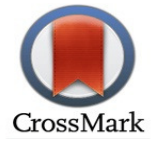


Sorghumis characterized by abundant sweet juice in the stalks that are used as a potential source of sugar and multipurpose industrial crop ${ }^{6}$. Sorghum is also useful commercially in breweries for fermented beverages, beer and malt production ${ }^{7}$. Some particular hybrids of sorghum (sorghum-sudangrass) are highly palatable and valued as forage crops. Sorghum is a great source of energy, carbohydrates, proteins, minerals and vitamins, which includes iron, potassium, magnesium and phosphorus in different quantities $^{8}$. The difficulty in processing sorghum, and its low food/nutritional value (12\% protein, $3 \%$ fat and $70 \%$ carbohydrate) due to the high tannin contents, which occur in the seed coats of brown sorghum grains are some the few drawbacks of sorghum utilization ${ }^{5}$.

Numerous nutritional and therapeutic values of sorghum as a plant has been reported ${ }^{9}$. These benefits had been linked to the presence of some nutrients and bioactive molecules present in sorghum ${ }^{10,11}$. Sorghum is usually subjected to processing methods that include but not limited to malting, fermentation, sprouting and genetic modification due to the relatively low nutritional value because of the formation of complexes between the anti-nutritional factors and food ingredients ${ }^{12}$. The effects of combined sprouting and fermentation on five varieties of sorghum was earlier reported to improve protein digestibility of sorghum seeds ${ }^{13}$. There is need to examine the extent at which these benefits are available during consumption since the seeds are not eaten raw as it is in nature but subjected to processing like fermentation or heating and drying to improve the nutritional profile, reduce anti-nutritional factors and improve the antioxidant content of sorghum ${ }^{14}$. This study focused on determining the effects of these relevant processing methods during different extraction techniques on tannin and the antioxidant status of the sorghum seeds.

\section{Chemicals}

\section{EXPERIMENTAL}

The methanol, ethanol, sulphuric acid, Folin Ciocalteure agent, tannic acid, sodium hydroxide, gallic acid, sodium carbonate, alcohol ferric chloride, potassium chloride, hydrochloric acids, 2,2- diphenyl-1picrylhydrazyl (DPPH) used in this study were obtained from Sigma Corporation, USA and are of analytical grade.

\section{Collection and Preparation of Sorghum Seeds}

The sorghum grains were directly purchased from a local farm in Oyo State, Nigeria $\left(7^{\circ} 19^{\prime} 60^{\prime \prime} \mathrm{N}\right.$ and $4^{\circ} 4^{\prime} 0^{\prime \prime}$ E). The preparation and cleaning process was carried out as described by Afolabi, Jolaoluwa, Amosun, Awogbindin ${ }^{10}$.

\section{Processing of Sorghum Seeds}

The collected sorghum seeds were processed into fermented, chaff and oven-dried sorghum while the finely ground sorghum seeds without any form of processing that served as control. For the fermented sorghum, the fermentation process was carried out as described by Afolabi, Jolaoluwa, Amosun, Awogbindin ${ }^{10}$. The filtering and oven-drying of the resulting extract for 6 hours at $40{ }^{\circ} \mathrm{C}$ produced the dried fermented sorghum seed sample. Following the fermentation process, the chaff (or seed coats) obtained after filtration was oven-dried at $40{ }^{\circ} \mathrm{C}$ for 6 hours to give the ordinary sorghum chaff sample. The oven dried sorghum was made by soaking an aliquot of $400 \mathrm{ml}$ of finely ground sorghum seeds in $800 \mathrm{ml}$ of water at room temperature for 12 hours. The samples were then divided into four portions and dried $^{15}$. The sorghum samples (OVD-0) were mainly air-dried at ambient temperature $\left(26-35^{0} \mathrm{C}\right)$ for a period of 2-3 days while the remaining portions of the sorghum seeds were oven dried at $100{ }^{\circ} \mathrm{C}$ for 30 minutes (OVD-30), 60 minutes (OVD-60) and 120 minutes (OVD-120) before analysis.

\section{Procedure for Preparation of Sorghum Extract}

An aliquot of $10 \mathrm{ml}$ of the appropriate solvent (methanol, ethanol and water) was added to $0.5 \mathrm{~g}$ of sorghum seed sample in a $50 \mathrm{ml}$ centrifuge tube, the sample solution was kept in a shaker for 2.0 hours at $100 \mathrm{rpm}$. The solvent extracts were thereafter incubated overnight at $-20{ }^{\circ} \mathrm{C}$. The centrifugation of the extracts was done at $700 \mathrm{x}$ g for 10 minutes before subjecting the samples to analyse. The three different samples were stored in the dark at $-20{ }^{\circ} \mathrm{C}$ until further biochemical analysis following the procedure of Awika, Rooney, Wu, Prior, Cisneros-Zevallos ${ }^{16}$. 


\section{Determination of Total Tannin Content}

Total tannin content was assayed as described by Prabhavathi, Prasad, Jayaramu ${ }^{17}$. An aliquot of $3.75 \mathrm{ml}$ of distilled water was added to $0.5 \mathrm{ml}$ of sample, following this was the addition of $0.5 \mathrm{ml}$ of sodium carbonate solution (35\%). The sample absorbance was measured at $725 \mathrm{~nm}$, and the concentration of tannin was extrapolated from a prepared standard graph of tannic acid $\left(\mathrm{R}^{2}=0.9714\right)$.

\section{Determination of Total Phenol Content}

Total phenol content was assayed as described by Afolabi, Ofobrukweta ${ }^{18}$. An aliquot of $0.8 \mathrm{ml}$ of FolinCiocalteu reagent was added to $0.2 \mathrm{ml}$ of the sample in a test tube, followed by the addition of $2.0 \mathrm{ml}$ of sodium carbonate solution $(7.5 \%$ ), and $7.0 \mathrm{ml}$ of distilled water. The sample mixture was incubated in the dark for 2 hours. The sample absorbance was measured at $765 \mathrm{~nm}$ and the concentration of total phenol was extrapolated from a standard graph of gallic acid $\left(\mathrm{R}^{2}=0.9997\right)$.

\section{Determination of Total Flavonoid Content}

Total flavonoid content was assayed as described by Devi, Kumar, Das ${ }^{19}$. An aliquot of $0.5 \mathrm{ml}$ of the sample was mixed with $1.5 \mathrm{ml}$ of ethanol (95\% purity), followed by the addition of $2.8 \mathrm{ml}$ distilled water, $0.1 \mathrm{ml}$ of potassium acetate solution $(1.0 \mathrm{M})$ and $0.1 \mathrm{ml}$ of aluminum chloride hexahydrate solution $(1.0$ M). The sample mixture was allowed to incubate in the dark for 40 mins at room temperature. The sample absorbance was measured at $415 \mathrm{~nm}$, and the concentration of total flavonoid was extrapolated from a standard graph of quercetin $\left(\mathrm{R}^{2}=0.9947\right)$.

\section{Determination of Free Radical DPPH Scavenging Activity}

The procedure described by Liu, Zhang, Yang, $\mathrm{Xu}^{20}$ was used for the determination of free radical DPPH antioxidant value. An aliquot of $2.9 \mathrm{ml}$ of DPPH-methanol solution $(1.0 \mathrm{mg} / \mathrm{mL})$ was added to $0.1 \mathrm{ml}$ of sample. The sample mixture was allowed to incubate for 30 minutes at $25{ }^{\circ} \mathrm{C}$. Methanol was used as a blank. The absorbance of the sample was measured at $517 \mathrm{~nm}$, and the concentration of DPPH value was extrapolated from an L-ascorbic acid standard graph $\left(\mathrm{R}^{2}=0.9967\right)$.

\section{Procedure for Determination of Total Polyphenol Content}

The procedure described by Afolabi, Ofobrukweta ${ }^{18}$ was used to assay for total polyphenol content. 5.5 $\mathrm{ml}$ of water was mixed with $0.5 \mathrm{ml}$ of sample extract and $0.5 \mathrm{ml}$ of Folin-Ciocalteu reagent was added. The solution was left standing for 30 minutes. After that, $0.5 \mathrm{ml}$ of standard sodium carbonate solution $(2.139 / \mathrm{ml})$ was added and the sample mixture was incubated at $37{ }^{\circ} \mathrm{C}$ for 60 minutes. Catechol was used as a standard. The absorbance of both standard and samples was measured at $700 \mathrm{~nm}$. The total polyphenol concentration was extrapolated from a standard graph $\left(R^{2}=0.8398\right)$.

\section{Statistical Analysis}

All experiments were carried out in triplicate. The mean \pm standard error of mean values and the statistical significance of the results were determined by one-way ANOVA using GraphPad Prism variant 5.00 for windows statistical package (GraphPad Software, USA). The significant values were those with $\mathrm{P}<0.05$ confidence level.

\section{RESULTS AND DISCUSSION}

This study was carried out to measure the effects that processing techniques on sorghum, as well as the effects of solvents such as ethanol, methanol and water on the optimal antioxidant benefits of sorghum.

\section{Total Tannin Content}

In our study, the levels of tannins were significantly reduced $(\mathrm{p}<0.05)$ by fermentation and the ovendrying process of sorghum seeds (Fig.-1). Although, tannins extracted with methanol were more preserved from destruction by fermentation, and the increasing period of oven-drying up to 120 mins. This preservation pattern was less efficient when the tannins from the sorghum seeds were extracted with ethanol and water for 30-60 mins. Fermentation and oven-drying method of processing sorghum seeds facilitated the general reduction in the value of antinutrients tannins (Fig.-1). The tannins extracted with 
methanol were minimally destroyed by fermentation, and as the period of oven-drying was extended from 30 mins to 120 mins. This reduction pattern was conspicuously observed for tannins extracted with ethanol, and the aqueous solution for a period of fewer than 120 mins. Processing techniques such as soaking and fermentation were reported to be the best for complete removal of tannins in sorghum, which contains condensed tannin with no traces of hydrolysable tannins ${ }^{21,22}$. Sorghum containing tannins reduces calorie in the body and therefore reduces body weight in animals ${ }^{23,24}$. The lower the quantities of tannin in sorghum, the higher the nutritional value of the sorghum. Tannins are known to bind to and lower the digestibility of different nutritional values and negatively affecting the productivity of animals $^{21,25}$.

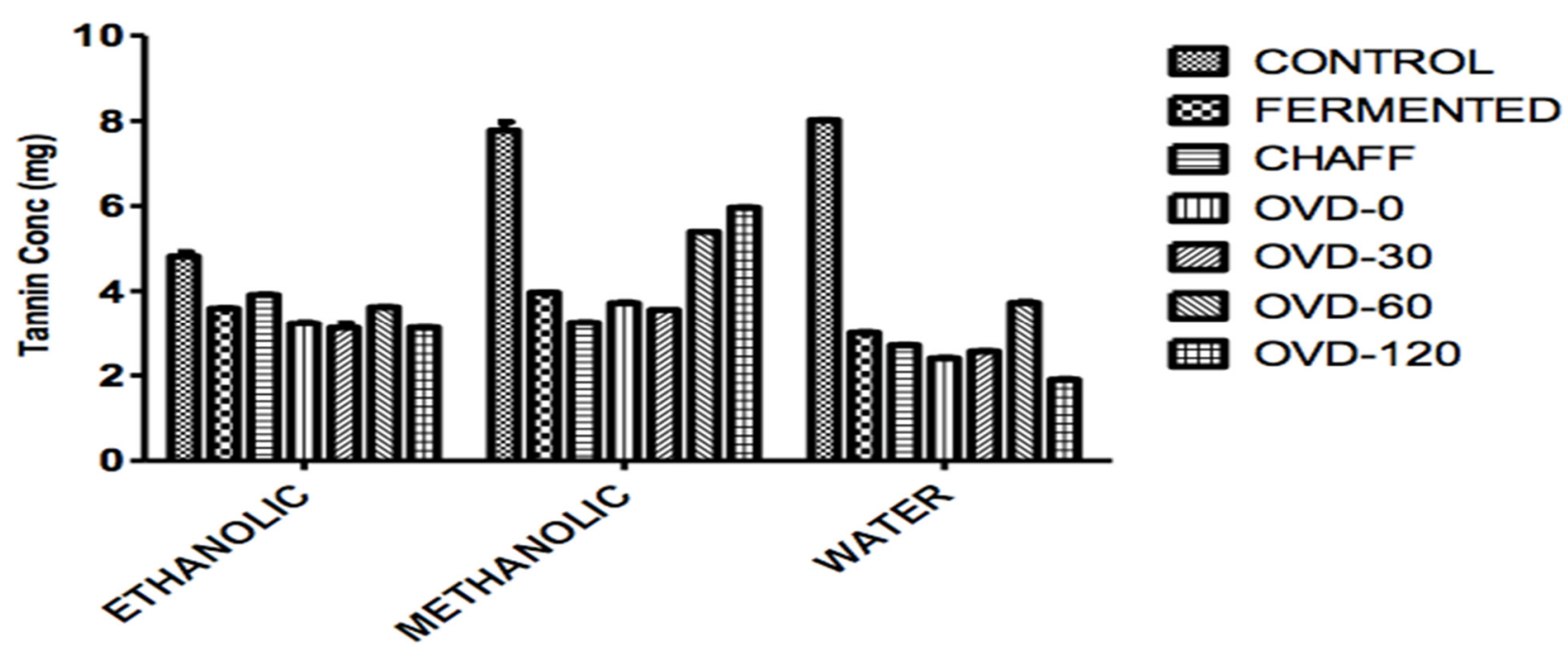

Fig.-1: The Effect of Processing Methods on the Total Tannin Contents of Sorghum Seeds.

\section{Total flavonoid content}

The flavonoids levels of ethanol and the ethanol extracts of sorghum seeds were significantly reduced $(\mathrm{p}<0.05)$ by oven drying (Fig.-2). This reduction, enhanced progressively with the extension of the period of drying when extracted with methanol. Also, the reduction was noted only at 120 mins of drying when extracted with ethanol. Also, the amount of flavonoids extracted was highest in methanol extracts of 30 mins oven-dried sorghum seeds, followed by that of the chaff extracted with ethanol (Fig.-2). This study has shown that flavonoids are best extracted in sorghum seeds when processed with 30 mins oven drying and extracted with methanol solvent, while ethanolic extraction alone is best for the seed chaff (Fig.-2). Flavonoids are polyphenolic water-soluble molecules containing 15 carbon atoms that are present in plants. They have various biological activities such as antioxidant, anti-inflammatory, anti-allergic, anticarcinogenic, anti-mutagenic and modulatory effects on enzymatic activities. Flavonoids possess high antioxidant activities that can protect the body system against free radical and other diseases such as arteriosclerosis and diabetes ${ }^{9,26-28}$.

\section{Total Phenolic Content}

The amount of phenolic present in sorghum seeds extracted with both ethanol and methanol significantly increased $(\mathrm{p}>0.05)$ with a progressive period of oven-drying. Also, the phenolic contents in the seeds were reduced significantly $(\mathrm{p}<0.05)$ when extracted with an aqueous solution (Fig.-3).The extent of ovendrying has little or no effects on the phenolic recovered with an aqueous solution. Although, the amount of phenolic recovered was best enhanced when both the sorghum seeds and the chaff are mainly extracted with an aqueous solution (Fig.-3). Also, the continuous increase in the amount of phenolic recovered, which depends on the duration of exposure to the drying temperature may be due to the breakdown of phenolic bounded to other macromolecules by the heat of drying ${ }^{29}$. Sorghum has been shown to contain an esterified form of total phenol that can only be extracted by alkaline hydrolysis, since they are bound 
RASĀYAN J. Chem.

Vol. 12 | No. 2 |523 - 530| April - June | 2019

with the cell wall component. This form is considered unavailable for absorption. Phenolic acids that are potentially bioavailable can increase the beneficial effects associated with consuming whole grains ${ }^{23}$.

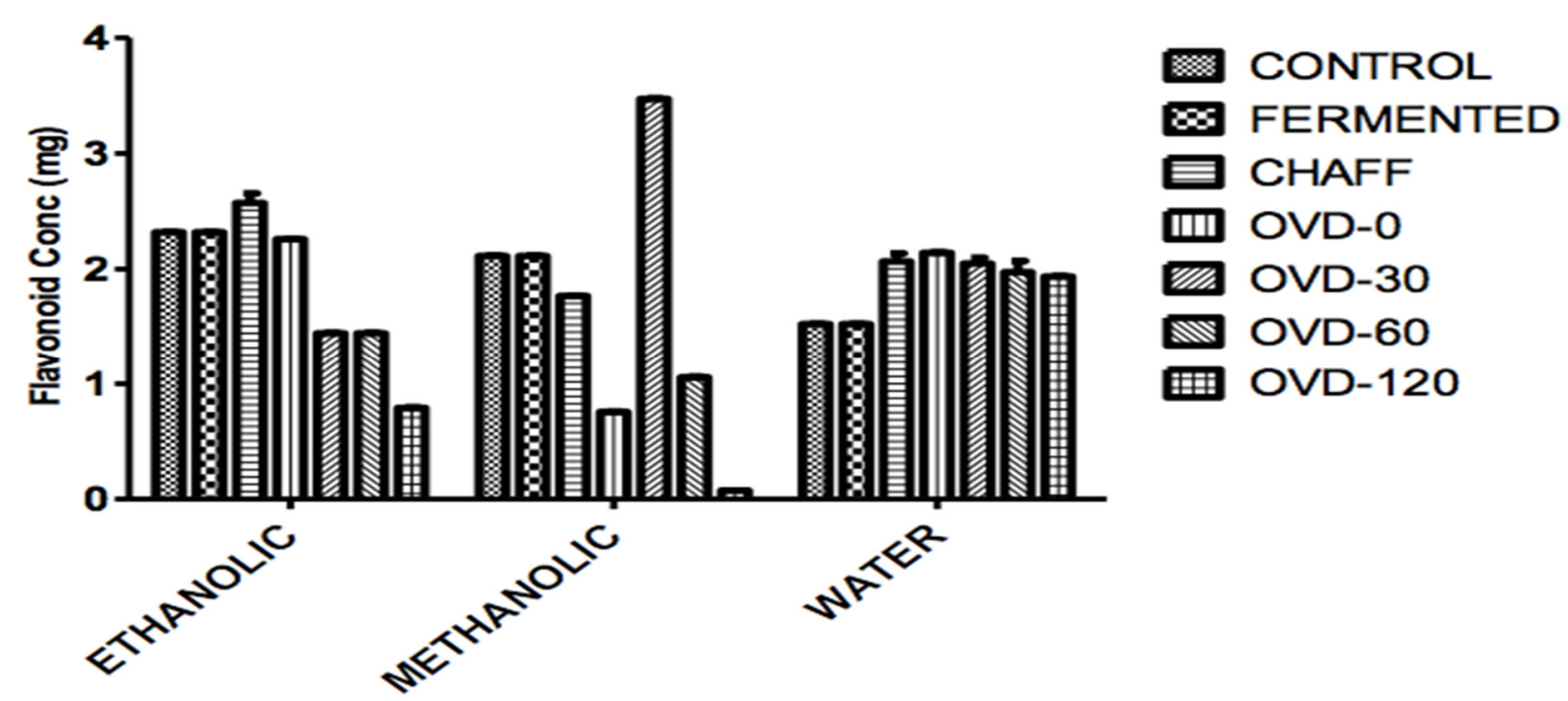

Fig.-2: The Effect of Processing Methods on the Total Flavonoid Contents of Sorghum Seeds.

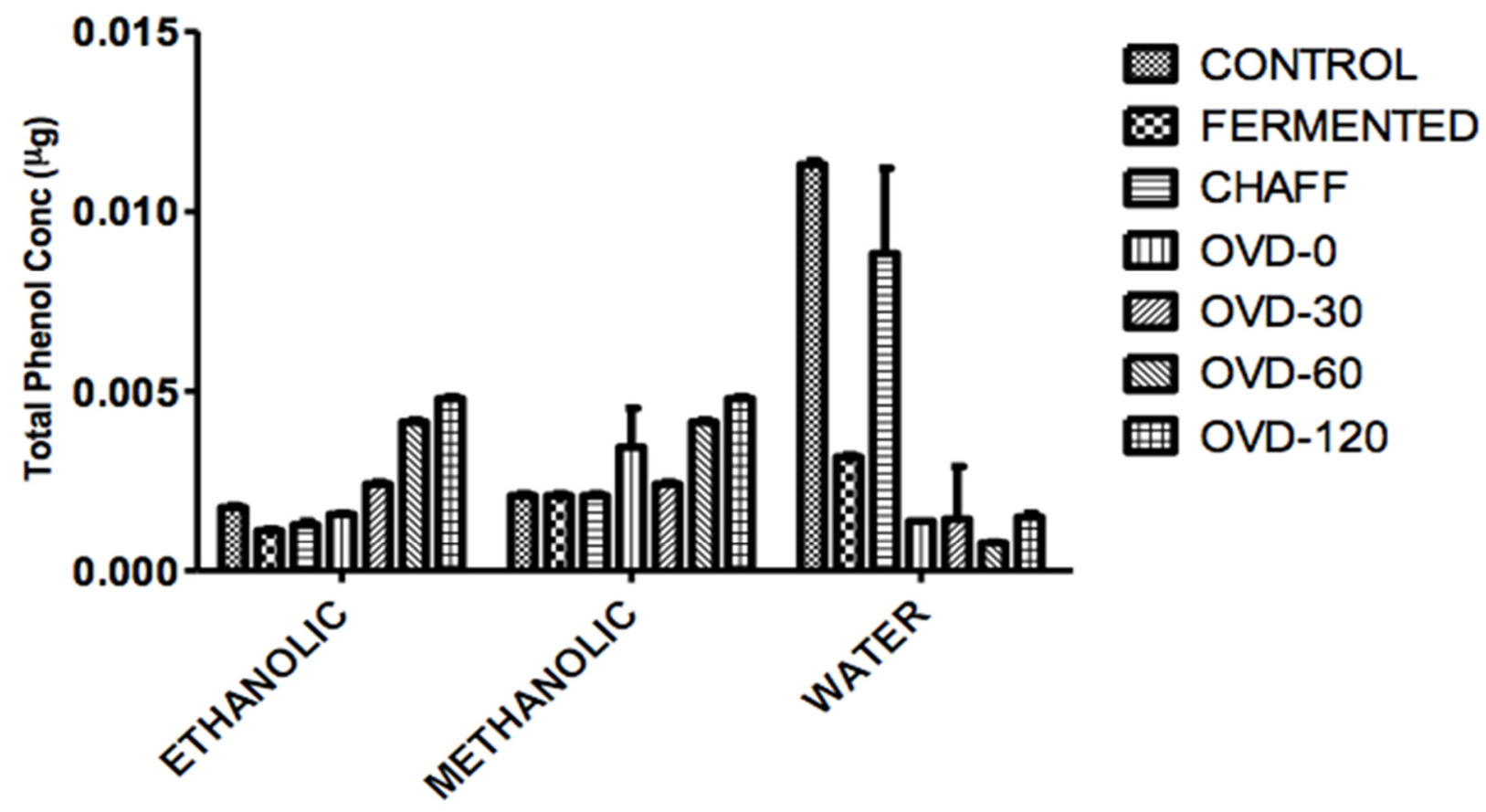

Fig.-3: The Effect of Processing Methods on the Total Phenolic Contents of Sorghum Seeds.

\section{Total Polyphenolic Content}

The amount of polyphenols present in the sorghum seeds was significantly increased $(\mathrm{p}<0.05)$ by ethanol extraction when treated with air-drying (OVD-0), and by aqueous extraction of the chaff (Fig. 4). This study suggests that the polyphenols content in sorghum seeds has to be processed with air-drying to make them optimally soluble for extraction in ethanol, while those of the chaff is most soluble for recovery in water (Fig.-4). Polyphenols are the most effective antioxidative component in plant foods, with red sorghum having a very high polyphenolic content among other grains ${ }^{23}$. Also, the seed coat has been proven to contain polyphenolic compounds that are combined with other flavonoids such as anthocyanin and anthocyanidin ${ }^{30-31}$. 


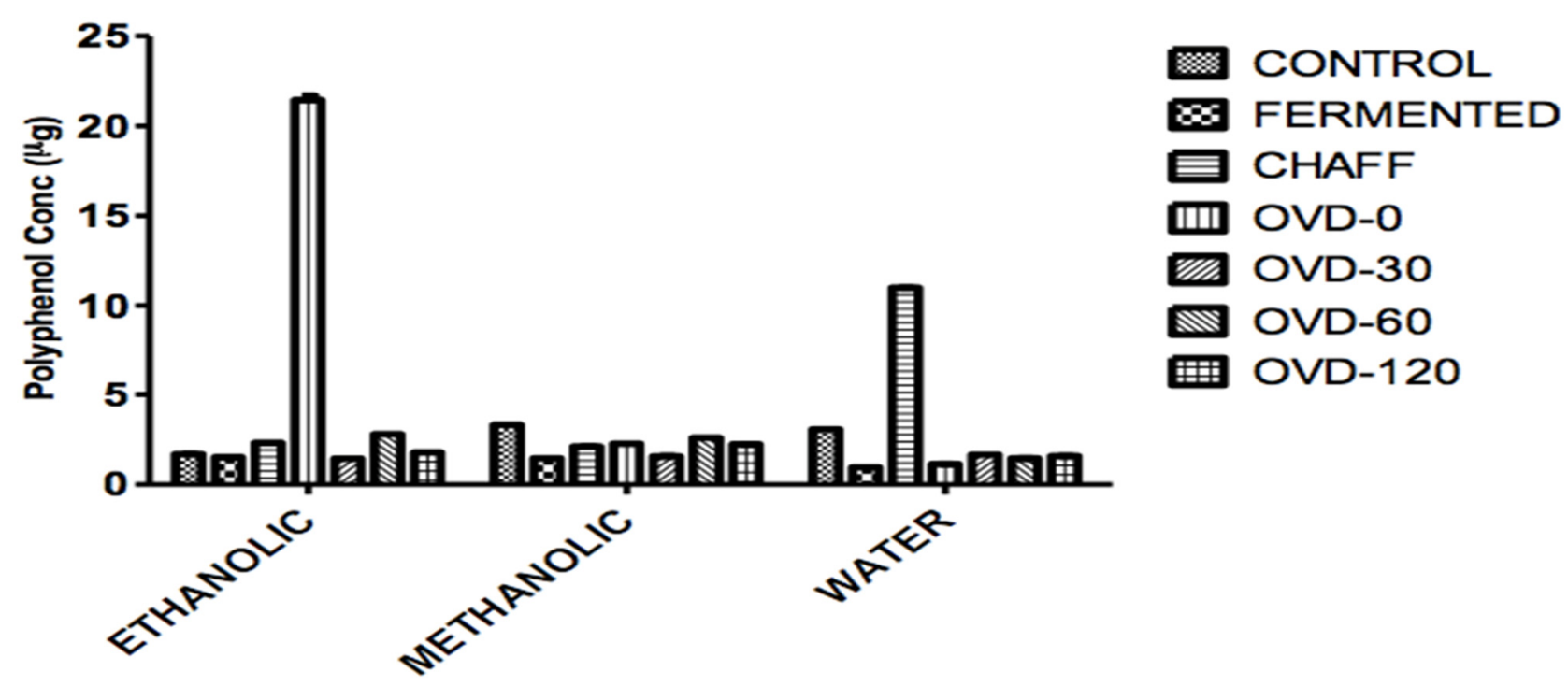

Fig.-4: The Effect of Processing Methods on the Total Polyphenol Contents of Sorghum Seeds.

\section{DPPH Free Radical Scavenging Activity}

The DPPH scavenging activities were reduced significantly $(\mathrm{p}<0.05)$ in the ethanolic extracts of the sorghum seeds when subjected to all the various processing methods (Fig. 5). On the contrary, the DPPH scavenging activity was increased significantly $(\mathrm{p}<0.05)$ by the processing methods when subjected to either aqueous or methanolic extraction (Fig.-5). This study reveals that optimal antioxidant ability to scavenge for free radicals can best be attained when the sorghum seeds are extracted with ethanol; when either the chaff or sorghum seeds subjected to air-drying is extracted with methanol; and when the seeds are fermented and extracted with an aqueous solution (Fig.-5). Thus, the fermented sorghum seeds are most suitable for dietary purposes since the seeds are usually processed with water for consumption ${ }^{32}$. The latter two treatments are recommended for pharmacological and medicinal purposes. Higher antioxidant activities were previously reported in methanolic extracts of sorghum compared to other solvents ${ }^{33}$. The antioxidant activity and phytochemical properties of sorghum seeds contribute greatly to their health benefits. It reduces harmful effects by modification of enzyme activities and cell signaling pathways $^{33}$.

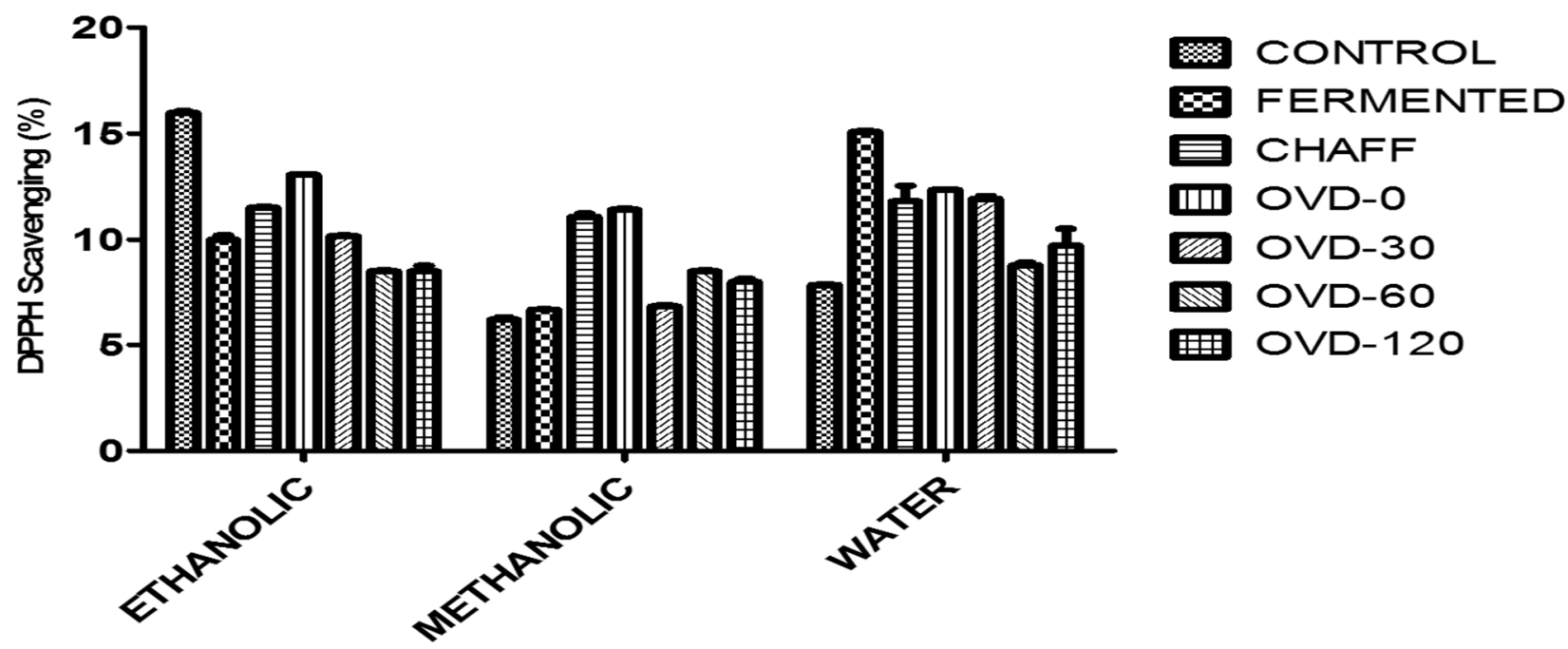

Fig.-5: The Effect of Processing Methods on the DPPH Antioxidant Scavenging Activities of Sorghum Seeds. 
RASĀYAN J. Chem.

Vol. 12 | No. 2 |523 - 530| April - June | 2019

\section{CONCLUSION}

Processing of sorghum seeds with the aid of fermentation or oven-drying techniques effects modifications on biomolecules present in the plant food leading to the depletion of anti-nutrients, enhancement of the antioxidant status and health benefits. Also, optimal antioxidant benefits can best be attained when the sorghum seeds are extracted with ethanol; when either the sorghum seeds are subjected to air-drying or the chaff is extracted with methanol; and when the seeds are fermented and combined with extraction using aqueous solution. The fermented sorghum seeds are most suitable for dietary purposes since the seeds are usually processed with water for consumption. The two previous treatments are recommended for pharmacological and medicinal purposes.

\section{ACKNOWLEDGMENT}

Authors appreciate the management of Covenant University, Ota, Nigeria for the financial support toward payment of the processing fee for this article. The technical support from Mr. Daniel Okeke and Miss Anuoluwa Awofeso is also highly appreciated.

\section{REFERENCES}

1. Food Security Department, Sorghum: Post-harvest Operations, pp. 1-32 (1999).

2. O. O. Obembe, J. O. Popoola, S. Leelavathi and S. V. Reddy, Biotechnol. Adv., 29(2), 210(2011), DOI: $10.1016 /$ j.biotechadv.2010.11.004

3. P. Ojha, R. Adhikari, R. Karki, A. Mishra, U. Subedi and T. B. Karki, Food Sci. Nutr., 6(1), 47(2018), DOI: $10.1002 / \mathrm{fsn} 3.525$

4. A. A. M. Nour, M. A. E. M. Ibrahim, E. E. Abdelrhman, E. F. Osman, K. E. Khadir, N. F. Hussain, N. A. Abdallatif and A. A. Eldirany, American Journal of Food Science and Health., 1(4), 104(2015).

5. O. N. O. Mella, M.Sc. Thesis, Food Science and Technology Department, University of Nebraska, Lincoln, USA (2001).

6. USDA, "Plant guide for Sorghum (Sorghum bicolor L.)," https://plants.usda.gov/plantguide/pdf/pg_sobi2.pdf, [07 June, 2018] (2012).

7. A. Singh, S. Sharma and B. Singh, J. Cereal. Sci., 76, 131(2017), DOI: 10.1016/j.jcs.2017.06.003

8. M. H. Dicko, H. Gruppen, A. S. Traoré, A. G. J. Voragen and W. J. H. v. Berkel, African J. Biotechnol., 5(5), 384(2006).

9. T. D. Olawole, M. I. Okundigie, S. O. Rotimi, O. Okwumabua, and I. S. Afolabi, Front. Nutr., 5, 16 (2018), DOI: $10.3389 /$ fnut.2018.00016

10. I. S. Afolabi, A. F. Jolaoluwa, P. T. Amosun and V. O. Awogbindin, Ciencia E Tecnica Vitivinicola., 30(3), (2015), http://ciencia-e-tecnica.org/view.php?v=30\&i=3, [07 June, 2018]

11. D. A. Abugri, B. J. Tiimob, V. A. Apalangya, G. Pritchett and W. H. McElhenney, Food Chem., 138(1), 718(2013), DOI: 10.1016/j.foodchem.2012.09.149

12. N. A. Mohammed, I. A. M. Ahmed and E. E. Babiker, International Journal of Biological and Life Sciences., 7(1), 35 (2011).

13. M. B. Raihanatu, S. Modu, A. S. Falmata, Y. A. Shettima and M. Heman, Biokemistri., 23(3), 91(2011).

14. I. S. Afolabi, G. D. Marcus, T. O. Olanrewaju and V. Chizea, J Nat Prod., 4, 17(2011).

15. S. Lee, and J. Lee, Food Chem., 112(2), 316 (2009), DOI: 10.1016/j.foodchem.2008.05.065

16. J. M. Awika, L. W. Rooney, X. Wu, R. L. Prior and L. Cisneros-Zevallos, J Agric Food Chem., 51(23), 6657(2003), DOI: 10.1021/jf034790i

17. R. M. Prabhavathi, M. P. Prasad and M. Jayaramu, Adv. Appl. Sci. Res., 7(4), 11(2016).

18. I. S. Afolabi and K. Ofobrukweta, J. Med. Plants Res., 5(4), 3115(2011).

19. P. S. Devi, M. S. Kumar and S. M. Das, Biotechnol. Res. Int., 2012, 258787(2012), DOI: $10.1155 / 2012 / 258787$

20. Q. Liu, Y. J. Zhang, C. R. Yang and M. Xu, J. Agric. Food Chem., 57(2), 586(2009), DOI:10.1021/jf802974m 
21. J. R. N. Taylor, P. S. Belton, T. Beta and K. G. Duodu, J. Cereal. Sci., 59(3), 257(2014), DOI: $10.1016 /$ j.jcs.2013.10.009

22. V. H. Mulimani and D. Supriya, Plant Food Hum. Nutr., 46(3), 195(1994), DOI:10.1007/bf01088990

23. J. M. Awika and L. W. Rooney, Phytochemistry., 65(9), 1199(2004), DOI: 10.1016/j.phytochem.2004.04.001

24. G. A. Mohamed, S. R. M. Ibrahim, E. S. Elkhayat and R. S. El Dine, B-FOPCU, 52(2), 269(2014), DOI: $10.1016 /$ j.bfopcu.2014.05.001

25. S. A. Mir, M. A. Shah, S. A. Ganai, T. Ahmad and M. Gani, Journal of the Saudi Society of Agricultural Sciences., (2017), DOI: 10.1016/j.jssas.2017.04.003

26. S. M. Sinaga, S. Sudarmi, I. Iksen, K. Kevin and M. P. Sari, Rasayan J. Chem., 11(4), 1604(2018), DOI: 10.31788/RJC.2018.1144067

27. I. Fidrianny, A. Rahmawati and R. Hartati, Rasayan J. Chem.,11(4), 1628(2018), DOI: $10.31788 /$ RJC.2018.1143091

28. T. Okselni, A. Santoni, A. Dharma and M. Efdi, Rasayan J. Chem., 11(3), 1211(2018), DOI: 10.31788/RJC.2018.1133058

29. O. B. Oloyede and I. S. Afolabi, Bioscience Research Communication.,14(6), 8(2002).

30. J. R. Taylor and K. G. Duodu, J Sci Food Agric.,95(2), 225(2015), DOI: 10.1002/jsfa.6713

31. I. S. Afolabi, I. O. Osikoya, O. D. Fajimi, P. I. Usoro, D. O. Ogunleye, T. Bisi-Adeniyi, A. O. Adeyemi and B. T. Adekeye, BMC Complement Altern Med.,12, 262(2012), DOI: 10.1186/14726882-12-262

32. P. C. Anunciacao, L. M. Cardoso, J. V. P. Gomes, C. M. Della Lucia, C. W. P. Carvalho, M. C. Galdeano, V. A. V. Queiroz, R. C. G. Alfenas, H. S. D. Martino and H. M. Pinheiro-Sant'Ana, Food Chem.,221, 984(2017), DOI: 10.1016/j.foodchem.2016.11.065

33. T. Oki, M. Masuda, M. Kobayashi, Y. Nishiba, S. Furuta, I. Suda, and T. Sato, J. Agric. Food Chem.,50(26), 7524 (2002), DOI: 10.1021/jf025841z

[RJC-4066/2018] 